\title{
Pathobiological investigation of naturally infected canine rabies cases from Sri Lanka

S. Beck ${ }^{1 *}$, P. Gunawardena ${ }^{2}$ D. L. Horton ${ }^{4}$, D. J. Hicks ${ }^{1}$, D. A. Marston ${ }^{4}$, A. Ortiz-Pelaez ${ }^{3}$, A. R. Fooks ${ }^{4}$ and A. Núñez ${ }^{1}$

\begin{abstract}
Background: The recommended screening of rabies in 'suspect' animal cases involves testing fresh brain tissue. The preservation of fresh tissue however can be difficult under field conditions and formalin fixation provides a simple alternative that may allow a confirmatory diagnosis. The occurrence and location of histopathological changes and immunohistochemical (IHC) labelling for rabies in formalin fixed paraffin embedded (FFPE) canine brain is described in samples from 57 rabies suspect cases from Sri-Lanka. The presence of Negri bodies and immunohistochemical detection of rabies virus antigen were evaluated in the cortex, hippocampus, cerebellum and brainstem. The effect of autolysis and artefactual degeneration of the tissue was also assessed.

Results: Rabies was confirmed in 53 of 57 (93\%) cases by IHC. IHC labelling was statistically more abundant in the brainstem. Negri bodies were observed in 32 of $53(60.4 \%)$ of the positive cases. Although tissue degradation had no effect on IHC diagnosis, it was associated with an inability to detect Negri bodies. In 13 cases, a confirmatory Polymerase chain reaction (PCR) testing for rabies virus RNA was undertaken by extracting RNA from fresh frozen tissue, and also attempted using FFPE samples. PCR detection using fresh frozen samples was in agreement with the IHC results. The PCR method from FFPE tissues was suitable for control material but unsuccessful in our field cases.

Conclusions: Histopathological examination of the brain is essential to define the differential diagnoses of behaviour modifying conditions in rabies virus negative cases, but it is unreliable as the sole method for rabies diagnosis, particularly where artefactual change has occurred. Formalin fixation and paraffin embedding does not prevent detection of rabies virus via IHC labelling even where artefactual degeneration has occurred. This could represent a pragmatic secondary assay for rabies diagnosis in the field because formalin fixation can prevent sample degeneration. The brain stem was shown to be the site with most viral immunoreactivity; supporting recommended sampling protocols in favour of improved necropsy safety in the field. PCR testing of formalin fixed tissue may be successful in certain circumstances as an alternative test.
\end{abstract}

Keywords: Rabies canine histopathology immunohistochemistry hemi-nested reverse transcription polymerase chain reaction

\section{Background}

Rabies is a highly neurotropic virus which is thought to have the potential to infect most mammalian species [10]. There is an almost universal case fatality rate (approaching $100 \%$ ) in humans, for whom the predominant source of exposure leading to death is dog bites [14, 27]. Rabies continues to be a significant threat to human health in developing countries, with most human cases occurring in Africa and Asia [11]. There is also a need

\footnotetext{
* Correspondence: sbeck@rvc.ac.uk

${ }^{1}$ Pathology Department, Animal and Plant Health Agency, Weybridge, UK

Full list of author information is available at the end of the article
}

for effective rabies surveillance and diagnosis in Europe where there is a low potential risk of transmission to humans from the 7064 domestic animal and wildlife cases reported in 2013 (WHO Rabies bulletin) [20]. Even countries that are officially free of rabies such as the UK report rare, imported (quarantined) cases [21]. The ability to diagnose rabies virus in domestic animals and wildlife is the basis of most national reporting programs.

Canine rabies cannot be diagnosed by clinical presentation alone, which is often varied and may include nonspecific signs such as pyrexia, altered neurological function, ataxia and paralysis prior to death [29]. 
Seroconversion is not a useful antemortem test because it occurs late in the disease process and there are no specific gross lesions at post-mortem [36]. Confirmation of rabies infection requires laboratory testing of brain tissue. The standard methods for the diagnosis of rabies virus in animals are recommended by the OIE (World Health Organisation for Animal Health) [31, 36]. Histopathologic examination of infected brain tissue can be used to directly identify Negri bodies in neuronal cytoplasm, which is considered pathognomonic for rabies virus infection [23]. Negri bodies are observed concurrently with perivascular, non-suppurative inflammation, glial proliferation, neuronal degeneration and necrosis. The reduced sensitivity in comparison to immunological and molecular tests has resulted in this technique no longer being recommended for primary diagnosis by the WHO or OIE $[12,36]$.

Many new diagnostic techniques are available for rabies diagnosis $[9,12]$ but the recommended ('gold-standard') OIE-prescribed diagnostic assay for statutory diagnosis of rabies virus is the fluorescent antibody test (FAT). This test is a direct technique undertaken on impression smears of fresh brain tissue labelling viral nucleocapsid protein $[3,15,26]$. Obtaining suitable fresh samples without a cold chain and performing testing that requires specialised local equipment remains a challenge $[25,36]$. Tissue fixation provides a cheap and simple solution, by preserving samples taken in remote areas prior to laboratory analysis and also allows safe inactivation of the test material. The FAT can also be undertaken on glycerol preserved and formalin fixed tissue, with additional washing or proteolytic enzyme steps respectively, however this is less reliable then using fresh samples [36]. Immunohistochemical (IHC) methods on fixed tissues offer an alternative or additional confirmatory method to the FAT.

Heminested reverse transcription polymerase chain reaction (HnRT-PCR) and real time, Taqman reverse transcription polymerase chain reaction (Taqman RT-PCR) assays have been described [16, 17, 34]. These methods, have been reported to give $100 \%$ specificity and sensitivity [2] and Taqman RT-PCR is considered capable of detecting divergent, novel Lyssaviruses [16, 24]. PCR techniques are important confirmatory tests, often used in tandem with FAT [21], which may also be used when brain tissue is severely autolysed $[8,25]$. At present PCR is not recommended for routine diagnosis by the WHO/ OIE because of the requirement for exacting standards of quality control, but it has a crucial role in epidemiological analysis of virus type [13, 34, 36]. PCR is usually undertaken using fresh tissue, although HnRT-PCR has previously been unsuccessfully attempted using formalin fixed (non-paraffin embedded) tissue in a single case study [7]. PCR using viral RNA extracted from FFPE tissue would be a practical tool for rabies diagnosis where this is the only tissue available or further diagnostic confirmation is required.

A final consideration in rabies diagnosis is that viral antigen is not equally distributed throughout the brain tissue of rabies positive animals. A large case series involving multiple naturally infected species from South Africa, was tested by FAT. The brainstem was most often antigen positive in canine cases, while the hippocampus contained the largest deposits of antigen when positive [5]. Two small (10 naturally infected canids) case series suggested that viral antigen distribution is greater in the brainstem, compared to other supratentorial structures [30, 32]. Another small case series (3 naturally infected canids) suggested that the hippocampus contains the most intense signal [31]. The general anatomic location of viral antigen has also been assessed by IHC labelling in 21 rabies positive canine cases, in which the cerebellum and hippocampus most often contained positive neurones [1]. It is unknown if this variation is due to study design, stage of infection, strain differences or another factor. In murine models, infected with rabies virus or European bat lyssavirus type 1 and 2, IHC labelling revealed variation in viral antigen distribution, with the brainstem most often being positive [18, 19]. Street and laboratory ("fixed") rabies virus have been compared using a murine model, also with variation in antigen distribution and inflammation [33]. Sample site selection is therefore crucial. The current OIE recommendation is to collect the whole brain in a necropsy room and sample hippocampus, thalamus, cerebral cortex and medulla oblongata: a pool of tissues including the brain stem is advocated for FAT sampling $[5,36]$. Opening the cranium carries obvious risk for the operator and for this reason 'straw' techniques have been described for sampling in the field [36].

\section{Methods}

The aim of this study is to assess in a large series of naturally infected canine rabies cases the general anatomical location of classic histopathological changes and rabies viral antigen labelling using FFPE tissue, with an analysis of the effect of artefact on detecting these features. A subset of cases were tested for rabies viral RNA by Taqman RT-PCR and HnRT-PCR using both fresh and FFPE tissue.

\section{Case collection}

FFPE brain tissue was available from fifty seven canids submitted to the University of Peradeniya, Sri Lanka between the years of 2007-2011 (Table 1). The time for which this material was fixed prior to processing is unknown. The cases were suspected to be infected with rabies virus because of observed neurologic changes but 
no further clinical information was provided. The areas of the brain available for analysis varied between cases; fresh frozen tissue was available from thirteen cases.

\section{Histopathology and IHC}

Serial sections were cut at $4 \mu \mathrm{m}$ and either stained with haematoxylin and eosin (HE) for histopathological examination or labelled immunohistochemically for viral antigen as described [19].

\section{Histopathological (HE) analysis}

The general anatomic locations available for each case were recorded and evaluated separately as cerebrum, cerebellum, hippocampus and brain stem (including pons and medulla). The following histological features, observed in each anatomical location, were semiquantitatively graded $0-3$ by one observer (SB); (i) Perivascular cuffing (lymphocytes within the VirchowRobins space); (ii) Gliosis (glial nodule formation); (iii) Satellitosis and neuronophagia and (iv) Artefactual degradation (freezing and autolysis) [Fig. 1]. In addition the presence or absence of Negri bodies (intracytoplasmic, 1-27 $\mu \mathrm{m}$ round, eosinophilic inclusions) [23] was recorded for each location.

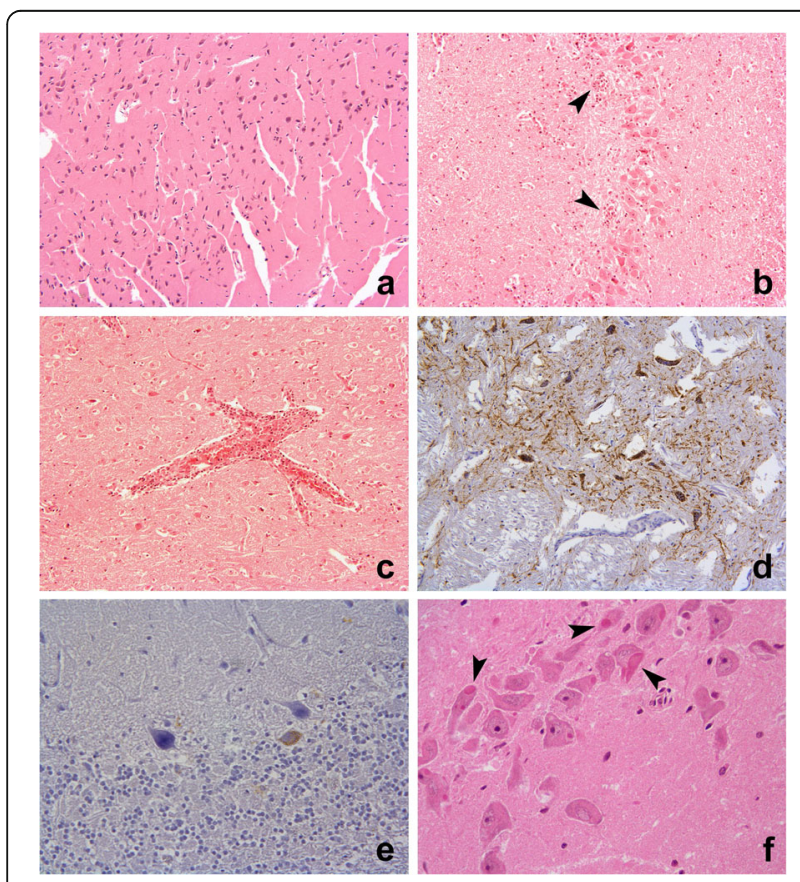

Fig. 1 Selected histopathology and immunohistochemistry photomicrographs. a; Cerebrum, case 39, tissue artefact score grade $3(\mathrm{HE} \times 10)$ b; Hippocampus, case 27, multifocal glial nodules grade 3 $(\mathrm{HE} \times 10)$ c; Brainstem, case 14, perivascular cuffing grade $2(\mathrm{HE} \times 10)$ d; Brainstem, case 29, positive grade 3 immunolabelling in grade 2 artefact tissue $(\mathrm{IHC} \times 10) \mathbf{e}$; Cerebellum, case 3, positive grade 1 immunolabelling in grade 2 artefact tissue $(\mathrm{IHC} \times 10) \mathbf{f}$; Hippocampus, case 12, neuronal intracytoplasmic eosinophilic viral inclusion (Negri body) in grade 2 artefact tissue $(\mathrm{IHC} \times 40)$

\section{IHC analysis}

Each anatomical location was semi-quantitatively graded 0-3 for the presence of specific neuronal immunolabelling by one observer (SB) [Fig. 1]. In the absence of suitable material on which to perform FAT, an IHC grade above 0 was considered a positive rabies diagnosis.

\section{PCR analysis (Taqman and HnRT-PCR)}

One assay of each kind was performed per fresh/frozen tissue pool (13 cases) or FFPE samples (Table 1). RNA was extracted from fresh brain tissue using the TriZol ${ }^{\mathrm{mm}}$ (Invitrogen, Life technologies, Paisley, UK) method following the manufacturer's instructions. RNA from FFPE samples was extracted from $80 \mu \mathrm{m}$ of each individual paraffin block available from those same 13 cases using the RecoverAll ${ }^{\mathrm{m}}$ kit (Ambion, Life technologies, Paisley, UK), and each block was tested separately one to three times. FFPE controls included a negative canine brain and two samples from a canine case that died in UK quarantine [21]. The pan-lyssavirus primer Jw12 was used to generate cDNA by reverse transcription. This was used to perform HnRT-PCR assays with primers Jw12 and Jw6dpl and Taqman RT-PCR assays with primers JW12 and N165-146, as previously described [16, 17, 34].

\section{Statistical analysis}

The sensitivity of Negri body detection for the diagnosis of rabies and the presence of perivascular cuffing, gliosis and satellitosis/neuronophagia were calculated per case and by general anatomic area. The median IHC labelling and HE scores for the general anatomic areas available from positive cases were compared using a KruskalWallis $\mathrm{H}$ test. Statistical significance was set at $p<0.05$. Post hoc pairwise comparisons were performed using Dunn's (1964) procedure with a Bonferroni correction for multiple comparisons; statistical significance was set at $p<0.0083$ and only corrected $p$-values are reported. The association between artefact score and IHC labelling score was analysed using a Spearman's rank-order correlation. A binary logistic regression was performed to ascertain the effect of artefact on the likelihood of detecting Negri bodies. PCR and IHC case results were compared but no statistical tests were required.

\section{Results}

The general anatomic areas available for examination from each case are contained in Table 1 . There was a mean of 2.3 anatomic areas per case (range 1-4) with 22 cases having a single anatomic area studied (20 positive, 2 negative), 9 with 2 anatomic areas ( 9 positive, 0 negative), 15 with 3 (14 positive, 1 negative) and 11 with 4 (10 positive, 1 negative). Fifty three of fifty seven cases 
Table 1 Summary of results for individual animals

\begin{tabular}{|c|c|c|c|c|c|c|c|c|c|c|c|c|c|}
\hline \multirow[t]{2}{*}{ Case } & \multicolumn{3}{|c|}{ Cerebrum } & \multicolumn{3}{|c|}{ Hippocampus } & \multicolumn{3}{|c|}{ Cerebellum } & \multicolumn{3}{|c|}{ Brainstem } & \multirow{2}{*}{$\begin{array}{l}\text { Pooled } \\
\text { Fresh } \\
\text { PCR }\end{array}$} \\
\hline & $\overline{N B^{b}}$ & $\mathrm{IHC}$ & Path $^{\text {d }}$ & $\overline{\mathrm{NB}}$ & $\mathrm{IHC}$ & Path & $\overline{\mathrm{NB}}$ & $\mathrm{IHC}$ & Path & $\overline{N B}$ & $\mathrm{IHC}$ & Path & \\
\hline 1 & + & ++ & $1 / 2 / 3 / 2$ & $\mathrm{~N} / \mathrm{a}^{\mathrm{a}}$ & $\mathrm{N} / \mathrm{a}$ & N/a & $\mathrm{N} / \mathrm{a}$ & $\mathrm{N} / \mathrm{a}$ & $\mathrm{N} / \mathrm{a}$ & N/a & $\mathrm{N} / \mathrm{a}$ & $\mathrm{N} / \mathrm{a}$ & N/a \\
\hline 2 & - & + & $1 / 3 / 2 / 2$ & N/a & $\mathrm{N} / \mathrm{a}$ & $\mathrm{N} / \mathrm{a}$ & N/a & N/a & $\mathrm{N} / \mathrm{a}$ & N/a & N/a & N/a & N/a \\
\hline 3 & $\mathrm{~N} / \mathrm{a}$ & N/a & N/a & N/a & N/a & N/a & - & + & $2 / 0 / 1 / 2$ & N/a & N/a & N/a & N/a \\
\hline 4 & + & ++ & $0 / 3 / 2 / 2$ & + & ++ & $0 / 3 / 2 / 2$ & + & +++ & $1 / 2 / 1 / 0$ & - & ++ & $0 / 3 / 2 / 2$ & N/a \\
\hline 5 & - & + & $1 / 2 / 2 / 1$ & - & ++ & $1 / 2 / 2 / 1$ & - & + & $2 / 1 / 1 / 2$ & N/a & N/a & $\mathrm{N} / \mathrm{a}$ & N/a \\
\hline 6 & - & - & $0 / 2 / 2 / 2$ & - & - & $0 / 2 / 2 / 1$ & - & - & $0 / 0 / 0 / 2$ & - & - & $0 / 1 / 1 / 1$ & - \\
\hline 7 & $\mathrm{~N} / \mathrm{a}$ & N/a & $\mathrm{N} / \mathrm{a}$ & - & + & $1 / 2 / 1 / 2$ & $\mathrm{~N} / \mathrm{a}$ & N/a & N/a & - & +++ & $1 / 2 / 1 / 2$ & N/a \\
\hline 8 & - & - & $0 / 1 / 1 / 2$ & N/a & $\mathrm{N} / \mathrm{a}$ & $\mathrm{N} / \mathrm{a}$ & - & - & $0 / 2 / 2 / 0$ & - & - & $0 / 1 / 1 / 2$ & N/a \\
\hline 9 & - & - & $0 / 1 / 1 / 2$ & N/a & $\mathrm{N} / \mathrm{a}$ & N/a & N/a & N/a & N/a & - & + & $2 / 2 / 2 / 1$ & + \\
\hline 10 & N/a & N/a & $\mathrm{N} / \mathrm{a}$ & - & ++ & $0 / 2 / 1 / 1$ & - & ++ & $0 / 1 / 0 / 1$ & + & +++ & $1 / 2 / 1 / 2$ & N/a \\
\hline 11 & N/a & N/a & N/a & N/a & N/a & $\mathrm{N} / \mathrm{a}$ & N/a & N/a & N/a & - & +++ & $1 / 2 / 2 / 1$ & + \\
\hline 12 & $\mathrm{~N} / \mathrm{a}$ & N/a & N/a & + & +++ & $1 / 2 / 2 / 2$ & N/a & N/a & $\mathrm{N} / \mathrm{a}$ & N/a & N/a & $\mathrm{N} / \mathrm{a}$ & N/a \\
\hline 13 & - & ++ & $2 / 1 / 1 / 2$ & N/a & N/a & $\mathrm{N} / \mathrm{a}$ & $\mathrm{N} / \mathrm{a}$ & N/a & N/a & N/a & N/a & N/a & + \\
\hline 14 & N/a & N/a & N/a & - & - & $1 / 2 / 2 / 0$ & - & ++ & $1 / 1 / 1 / 1$ & - & ++ & $2 / 2 / 2 / 1$ & N/a \\
\hline 15 & - & +++ & $1 / 1 / 1 / 2$ & $\mathrm{~N} / \mathrm{a}$ & N/a & N/a & + & +++ & $1 / 2 / 1 / 2$ & + & +++ & $1 / 1 / 1 / 1$ & N/a \\
\hline 16 & - & + & $0 / 2 / 1 / 2$ & - & ++ & $2 / 3 / 2 / 2$ & - & + & $2 / 2 / 1 / 1$ & - & ++ & $2 / 3 / 3 / 0$ & N/a \\
\hline 17 & - & ++ & $0 / 2 / 1 / 1$ & - & ++ & $0 / 2 / 1 / 1$ & - & ++ & $0 / 1 / 1 / 1$ & - & +++ & $2 / 3 / 2 / 1$ & N/a \\
\hline 18 & - & +++ & $1 / 2 / 2 / 0$ & $\mathrm{~N} / \mathrm{a}$ & $\mathrm{N} / \mathrm{a}$ & N/a & + & ++ & $1 / 1 / 1 / 1$ & - & +++ & $2 / 2 / 2 / 0$ & + \\
\hline 19 & - & +++ & $0 / 2 / 1 / 1$ & - & ++ & $0 / 1 / 2 / 0$ & N/a & N/a & $\mathrm{N} / \mathrm{a}$ & N/a & N/a & $\mathrm{N} / \mathrm{a}$ & + \\
\hline 20 & - & + & $0 / 1 / 1 / 1$ & N/a & $\mathrm{N} / \mathrm{a}$ & N/a & N/a & N/a & N/a & N/a & N/a & $\mathrm{N} / \mathrm{a}$ & + \\
\hline 21 & + & ++ & $1 / 2 / 3 / 1$ & + & +++ & $0 / 2 / 1 / 0$ & N/a & N/a & $\mathrm{N} / \mathrm{a}$ & + & +++ & $0 / 2 / 2 / 0$ & + \\
\hline 22 & N/a & N/a & $\mathrm{N} / \mathrm{a}$ & N/a & $\mathrm{N} / \mathrm{a}$ & N/a & N/a & N/a & $\mathrm{N} / \mathrm{a}$ & + & +++ & $2 / 2 / 2 / 1$ & N/a \\
\hline 23 & - & - & $2 / 1 / 2 / 2$ & + & ++ & $2 / 2 / 2 / 2$ & - & - & $0 / 1 / 1 / 2$ & + & ++ & $2 / 2 / 2 / 2$ & N/a \\
\hline 24 & + & ++ & $2 / 2 / 3 / 1$ & N/a & $\mathrm{N} / \mathrm{a}$ & N/a & N/a & N/a & $\mathrm{N} / \mathrm{a}$ & N/a & N/a & $\mathrm{N} / \mathrm{a}$ & N/a \\
\hline 25 & - & +++ & $2 / 2 / 1 / 1$ & + & +++ & $2 / 2 / 2 / 1$ & - & +++ & $3 / 1 / 1 / 0$ & - & +++ & $2 / 2 / 2 / 1$ & + \\
\hline 26 & + & ++ & $3 / 2 / 1 / 3$ & N/a & $\mathrm{N} / \mathrm{a}$ & N/a & N/a & N/a & N/a & N/a & N/a & N/a & + \\
\hline 27 & N/a & N/a & N/a & + & +++ & $0 / 3 / 3 / 0$ & + & +++ & $0 / 3 / 2 / 0$ & - & ++ & $1 / 3 / 3 / 0$ & + \\
\hline 28 & - & ++ & $3 / 2 / 2 / 2$ & N/a & $\mathrm{N} / \mathrm{a}$ & N/a & N/a & N/a & N/a & N/a & N/a & $\mathrm{N} / \mathrm{a}$ & N/a \\
\hline 29 & $\mathrm{~N} / \mathrm{a}$ & N/a & N/a & + & +++ & $1 / 3 / 2 / 2$ & N/a & N/a & N/a & + & +++ & $1 / 3 / 2 / 2$ & N/a \\
\hline 30 & + & +++ & $3 / 3 / 2 / 0$ & $\mathrm{~N} / \mathrm{a}$ & $\mathrm{N} / \mathrm{a}$ & $\mathrm{N} / \mathrm{a}$ & N/a & N/a & N/a & N/a & N/a & NA & N/a \\
\hline 31 & - & ++ & $2 / 3 / 2 / 2$ & + & ++ & $3 / 2 / 2 / 2$ & - & ++ & $1 / 2 / 1 / 2$ & N/a & N/a & $\mathrm{N} / \mathrm{a}$ & N/a \\
\hline 32 & - & ++ & $1 / 2 / 2 / 3$ & + & ++ & $2 / 2 / 2 / 2$ & N/a & N/a & N/a & - & ++ & $2 / 2 / 2 / 2$ & N/a \\
\hline 33 & - & + & $0 / 2 / 2 / 3$ & - & + & $1 / 0 / 0 / 3$ & - & + & $0 / 0 / 0 / 3$ & - & ++ & $1 / 0 / 0 / 3$ & N/a \\
\hline 34 & + & ++ & $2 / 3 / 3 / 0$ & $\mathrm{~N} / \mathrm{a}$ & $\mathrm{N} / \mathrm{a}$ & $\mathrm{N} / \mathrm{a}$ & + & ++ & $2 / 2 / 2 / 0$ & + & ++ & $2 / 2 / 2 / 0$ & + \\
\hline 35 & - & ++ & $1 / 3 / 2 / 2$ & + & ++ & $2 / 1 / 1 / 2$ & - & +++ & $2 / 2 / 2 / 3$ & - & ++ & $2 / 1 / 1 / 2$ & N/a \\
\hline 36 & + & ++ & $0 / 1 / 1 / 0$ & + & +++ & $0 / 1 / 1 / 0$ & + & ++ & $0 / 2 / 1 / 2$ & NA & NA & NA & N/a \\
\hline 37 & - & - & $0 / 1 / 1 / 0$ & - & ++ & $0 / 2 / 2 / 0$ & - & + & 0/0/0/1 & - & ++ & $3 / 3 / 2 / 0$ & N/a \\
\hline 38 & - & +++ & 0/0/0/3 & - & ++ & 0/0/0/3 & N/a & N/a & $\mathrm{N} / \mathrm{a}$ & N/a & N/a & N/a & N/a \\
\hline 39 & - & + & 0/0/0/3 & N/a & N/a & $\mathrm{N} / \mathrm{a}$ & N/a & N/a & N/a & N/a & N/a & $\mathrm{N} / \mathrm{a}$ & N/a \\
\hline 40 & - & + & $0 / 2 / 2 / 3$ & - & ++ & $2 / 3 / 2 / 3$ & $\mathrm{~N} / \mathrm{a}$ & N/a & N/a & N/a & N/a & N/a & + \\
\hline 41 & - & ++ & $0 / 2 / 2 / 3$ & + & ++ & $0 / 1 / 1 / 3$ & N/a & N/a & N/a & - & +++ & $1 / 3 / 3 / 2$ & $\mathrm{~N} / \mathrm{a}$ \\
\hline 42 & - & ++ & $2 / 2 / 0 / 3$ & + & ++ & $2 / 2 / 1 / 2$ & N/a & N/a & $\mathrm{N} / \mathrm{a}$ & - & ++ & $3 / 3 / 1 / 2$ & N/a \\
\hline 43 & + & +++ & $1 / 3 / 3 / 2$ & N/a & $\mathrm{N} / \mathrm{a}$ & $\mathrm{N} / \mathrm{a}$ & N/a & N/a & N/a & + & +++ & $1 / 3 / 2 / 2$ & N/a \\
\hline
\end{tabular}


Table 1 Summary of results for individual animals (Continued)

\begin{tabular}{|c|c|c|c|c|c|c|c|c|c|c|c|c|c|}
\hline 44 & - & + & $1 / 2 / 2 / 1$ & $\mathrm{~N} / \mathrm{a}$ & N/a & N/a & N/a & N/a & N/a & N/a & N/a & N/a & $\mathrm{N} / \mathrm{a}$ \\
\hline 45 & - & + & $0 / 2 / 1 / 2$ & $\mathrm{~N} / \mathrm{a}$ & N/a & N/a & N/a & N/a & N/a & N/a & N/a & N/a & $\mathrm{N} / \mathrm{a}$ \\
\hline 46 & - & + & 2/3/3/1 & - & + & $1 / 2 / 2 / 1$ & - & + & $2 / 1 / 1 / 0$ & - & +++ & $3 / 3 / 3 / 1$ & N/a \\
\hline 47 & + & ++ & $2 / 2 / 2 / 2$ & N/a & N/a & N/a & $\mathrm{N} / \mathrm{a}$ & N/a & N/a & N/a & N/a & N/a & $\mathrm{N} / \mathrm{a}$ \\
\hline 48 & + & ++ & $3 / 3 / 3 / 0$ & $\mathrm{~N} / \mathrm{a}$ & $\mathrm{N} / \mathrm{a}$ & $\mathrm{N} / \mathrm{a}$ & N/a & N/a & $\mathrm{N} / \mathrm{a}$ & N/a & N/a & $\mathrm{N} / \mathrm{a}$ & $\mathrm{N} / \mathrm{a}$ \\
\hline 49 & + & +++ & $3 / 3 / 3 / 1$ & $\mathrm{~N} / \mathrm{a}$ & N/a & N/a & + & ++ & $3 / 2 / 2 / 0$ & N/a & N/a & N/a & $\mathrm{N} / \mathrm{a}$ \\
\hline 50 & + & ++ & $3 / 3 / 3 / 1$ & + & +++ & $3 / 3 / 3 / 0$ & + & +++ & $1 / 2 / 2 / 2$ & N/a & N/a & N/a & $\mathrm{N} / \mathrm{a}$ \\
\hline 51 & + & +++ & $3 / 3 / 3 / 3$ & $\mathrm{~N} / \mathrm{a}$ & N/a & $\mathrm{N} / \mathrm{a}$ & N/a & N/a & $\mathrm{N} / \mathrm{a}$ & $\mathrm{N} / \mathrm{a}$ & N/a & N/a & $\mathrm{N} / \mathrm{a}$ \\
\hline 52 & - & - & 0/3/3/1 & $\mathrm{N} / \mathrm{a}$ & N/a & $\mathrm{N} / \mathrm{a}$ & N/a & N/a & $\mathrm{N} / \mathrm{a}$ & N/a & N/a & N/a & $\mathrm{N} / \mathrm{a}$ \\
\hline 53 & + & ++ & $2 / 2 / 1 / 2$ & $\mathrm{~N} / \mathrm{a}$ & N/a & N/a & N/a & N/a & N/a & N/a & N/a & N/a & $\mathrm{N} / \mathrm{a}$ \\
\hline 54 & + & +++ & $2 / 3 / 3 / 2$ & $\mathrm{~N} / \mathrm{a}$ & N/a & $\mathrm{N} / \mathrm{a}$ & N/a & N/a & $\mathrm{N} / \mathrm{a}$ & - & +++ & $1 / 2 / 2 / 2$ & $\mathrm{~N} / \mathrm{a}$ \\
\hline 55 & - & +++ & 0/3/3/0 & + & ++ & $0 / 3 / 3 / 0$ & + & +++ & $1 / 2 / 2 / 0$ & + & +++ & $0 / 3 / 3 / 0$ & $\mathrm{~N} / \mathrm{a}$ \\
\hline 56 & + & +++ & $2 / 3 / 3 / 0$ & N/a & N/a & $\mathrm{N} / \mathrm{a}$ & N/a & N/a & $\mathrm{N} / \mathrm{a}$ & N/a & $\mathrm{N} / \mathrm{a}$ & N/a & $\mathrm{N} / \mathrm{a}$ \\
\hline 57 & - & - & 0/0/0/3 & $\mathrm{N} / \mathrm{a}$ & N/a & N/a & N/a & N/a & N/a & N/a & $\mathrm{N} / \mathrm{a}$ & N/a & $\mathrm{N} / \mathrm{a}$ \\
\hline
\end{tabular}

Where two or more of the same anatomical area were available for analysis the highest scores are presented

a: Not available

b: Negri body observed (- or + )

c: Viral antigen immunohistochemical labelling score ( - to +++$)$

${ }^{d}$ : Perivascular cuffing score/ Gliosis score/ Satellitosis and neuronophagia score/ Artefact score

(93\%) were positive by IHC for rabies viral antigen in at least one anatomical area.

\section{Histopathology}

Perivascular cuffing (47/53; 88.7\%), glial proliferation (50/ 53; $94.3 \%)$ and satellitosis/neuronophagia (51/53; 96.2\%) were frequently found in rabies positive cases. The mean rank of perivascular cuffing scores were not statistically significantly different, $X^{2}[3]=6.054, p=.109$. Glial $\left(X^{2}(3)=18.376, p=<.001\right)$ and satellitosis/neuronophagia $\left(\chi^{2}(3)=17.686, p=.001\right)$ scores were statistically significantly different between general anatomical areas. Post hoc analysis revealed statistically significant differences in glial scores between the cerebellum (mean rank $=45.90$ ) and hippocampus (75.65) ( $p=.050)$, cerebellum and cerebrum (82.04) $(p=.001)$ and cerebellum and brainstem (mean rank $=90.51)(p=<.001)$. Overall the cerebellum had the lowest glial score in rabies positive cases. There were no statistically significant differences between other anatomical areas. Post hoc analysis revealed statistically significant differences in satellitosis/neuronophagia scores between the cerebellum (mean rank $=46.50$ ) and cerebrum (mean rank $=84.12)(p=.001)$ and cerebellum and brainstem (mean rank $=88.59)(p=.001)$.

The overall sensitivity of Negri body detection in rabies positive cases was $60.4 \%$ (32/53). Negri body detection was most sensitive in the hippocampus $(15 / 30 ; 50.0 \%)$ and least sensitive in the brain stem $(9 / 34 ; 26.5 \%)$. Inversely, perivascular cuffing in rabies positive cases was most and least commonly observed in the brainstem $(30 / 34 ; 88.2 \%)$ and hippocampus $(17 / 30 ; 56.7 \%)$ respectively. Negri bodies were not found in the negative IHC cases, however in one negative case there was histopathological evidence of granulomatous meningoencephalitis. In the remaining three negative cases a cause for clinical suspicion of rabies was not determined.

\section{Association between artefact grade and histopathology scores}

A binary logistic regression was performed to ascertain the effect of the presence of artefact on the likelihood of detecting Negri bodies. The artefact score was dichotomised as either no artefact (score 0 ) or artefact present (scores 1, 2 and 3). The logistic regression model was statistically significant, $\mathrm{x}^{2}[1]=8.672,(p=.003)$. The model explained $7.1 \%$ (Nagelkerke R2) of the variance in Negri body detection and correctly classified $67.7 \%$ of cases. Negri bodies were 0.34 times less likely to be detected in tissue with artefactual degeneration. Negri body detection sensitivity was almost twice as great ( $56.4 \%$ versus $30.8 \%$ ) when there was no artefact (grade 0) compared to artefact (grade 1,2 or 3). The sensitivities of perivascular cuffing, glial proliferation and satellitosis/neuronophagia varied by less than $10 \%$ between grades when there was artefact compared to when there was none. Therefore artefact did not significantly affect HE diagnosis of encephalitis, but reduced Negri body detection.

\section{IHC results analysis}

Specific immunolabelling was found within the perikaryon of infected neurones and within the neuropil in association with axonal processes. There was inter and intracase variability in specific patterns of labelling: including morphology, location and the number of 
neurones labelled, but detailed analysis was not appropriate in this series. A Kruskal-Wallis $\mathrm{H}$ test was conducted to determine if there were differences in rabies antigen IHC labelling scores between general anatomical areas: the brainstem $(n=34)$, cerebrum $(n=65)$, cerebellum $(n=24)$ and hippocampus $(n=30)$. IHC scores were statistically significantly different between the different general anatomic areas, $\chi^{2}[3]=15.859, p=.001$. Post hoc analysis revealed statistically significant differences in rabies antigen IHC labelling scores between the brainstem (mean rank $=101.37$ ) and hippocampus (73.88) $(p=.045)$, brainstem and cerebellum (66.94) $(p=.010)$ and the brainstem and cerebrum (69.41) $(p=.001)$. Overall, there were significantly greater IHC scores within the brainstem as compared to other areas. The differences between cerebrum, cerebellum and hippocampus were not statistically significant.

\section{Association between artefact grade and IHC}

A Spearman's rank-order correlation was performed to assess the relationship between artefact score and rabies virus IHC score. There was a moderate negative correlation between increasing artefact score and IHC score, $r_{s}$ $(162)=-.260(p=.001)$. Therefore higher artefact scores are associated with lower IHC scores. When a Spearman's rank-order correlation was run to assess the association between artefact score and rabies virus immunoreactivity (positive/negative) there was no statistically significant correlation between increasing artefact score and overall IHC score, $r_{s}(162)=-.089(p=.255)$. Therefore case diagnosis was not affected by increasing artefact score.

\section{PCR assays}

Of the 13 cases tested using fresh tissue, 12 were positive and one was negative for rabies. There was total agreement between IHC diagnosis (positive/negative) and the fresh tissue PCR test results. Despite multiple attempts, HnRT-PCR and Taqman RT-PCR assays were negative in the matching sample sets using FFPE tissue. Taqman RT-PCR, but not HnRT-PCR, produced positive results in the two FFPE samples used as positive technique control.

\section{Discussion}

The purpose of this study was to assess the distribution of rabies viral antigen and inflammatory changes within the general anatomical areas of the brain alongside an evaluation of the effect of artefact and suitability of FFPE tissue for molecular diagnosis of rabies virus. In this large canine case series Negri bodies were present in $60 \%$ (32 of 53) of the positive cases, which is similar to a relatively recent report [1]. Similarly, as previously reported in canine brain, Negri bodies were most often detected in the hippocampus [3, 23]. There have been reports of rare Negri body-like inclusions occurring in rabies negative canine brain, however in this series inclusions were not observed in IHC negative cases [26, 28].

The observation of Negri bodies was associated with lower scores of autolysis and freeze thaw artefact. Therefore, whilst of some value if no other method is available; the sensitivity of Negri body detection is such that other complementary tests must be employed to confirm or refute a diagnosis particularly in autolytic specimens.

The anatomical distribution of inflammation observed with HE staining is relevant to sampling site identification, pathogenesis and immunological studies. The pons and medulla have previously been identified as the site of greatest inflammation in a murine model and the brainstem has been described as the site of most intense inflammation in naturally infected paralytic forms of canine rabies [18, 19, 30]. In this series, rabies positive cases also exhibited perivascular cuffing, most frequently in the brain stem and least often within the hippocampus, where Negri bodies were more frequently detected. Negri bodies were least often identified in the brainstem; potentially this is because the inflammatory response is destructive and may obscure Negri body observation. The relationship between inflammation and paralytic or furious clinical presention has previously been described [30] but was not possible in this study because the clinical information was unavailable.

The cerebellar glial score was significantly lower than other areas and satellitosis/neuronophagia score was significantly greater in the cerebrum and brainstem. The relative increase in inflammation within the brainstem, as compared to other structures, may be related to the natural time course of infection, whereby it is infected via retrograde transport of virus antigen from a distal site of inoculation (eg bite wound) before the cerebellum/hippocampus. Therefore, earlier local infection results in increased upregulation of inflammatory cytokines and lymphocyte perivascular cuffing, resulting in more severe leukocyte recruitment and inflammation. This is supported by previous work where mice were inoculated in the foot pad with Lyssavirus: increased immunolabelling of CCL2, CCL5 and CXCL10 was identified in caudal brain regions, particularly the medulla and pons associated with more severe inflammatory changes [18].

The IHC labelling score for rabies viral antigen was significantly greater within the brainstem. This is in agreement with previous investigations using fresh tissue with FAT and IHC labelling $[5,30]$ although contrary to two much smaller canine series [1,31]. Viral entry into the brain is expected via the brainstem because natural canine infections occur from bites, either directly from a facial injury or via the spinal cord when limbs are affected. Other authors have suggested that the viral 
location in cholinergic rich areas of the brain is an intrinsic property of the rabies virus [32]. Subsequent further local spread to higher structures such as the cerebrum, hippocampus and cerebellum would then logically follow.

Viral antigen labelling score is greater within the brain stem, while Negri bodies are most frequently observed within the hippocampus. The reasons for this are unclear but this change may reflect the local destructive effects of inflammation within the brainstem (as previously discussed) that obscures Negri body visualisation, or simply the convenience of observing viral inclusions within large Purkinje neurones that are present in high numbers within the dentate gyrus. An undefined predisposition of Purkinje neurones to accumulate viral antigen, without an accompanying florid inflammatory response, cannot be excluded; but it would seem more likely that inflammation would follow viral antigen accumulation. It is therefore possible that the clinical effects of brain stem inflammation have supervened before hippocampal lesions have had time to progress and therefore the observed differences in the hippocampus and brain stem areas reflects the natural course of infection.

Less invasive necropsy techniques such as sampling the brain using a straw via the occipital route [5], has been validated for use in the field where full brain exposure and removal of the encephalon is impractical and carries an associated operator risk [36].

Artefactual degeneration was associated with reduced immunoreactivity, but it did not affect the overall positive or negative diagnosis. Formalin fixed tissue can be stored without undergoing further bacterial and autolytic degeneration prior to accessing laboratory facilities. Excessive cross-linking from prolonged formalin fixation may affect antigen retrieval, but this was not significant in the studied series [29]. Therefore IHC labelling of FFPE tissue offers an ideal method for rabies diagnosis when artefactual degeneration of fresh brain tissue is inevitable or where fresh tissue is not available from suspect cases.

Although FAT is the OIE prescribed tool for rabies diagnosis in animals there are reported weaknesses of the FAT: autolysis and bacterial contamination are known to substantially reduce sensitivity $[1,2,12]$ and formalin fixation may make a sample unsuitable for routine testing $[29,36]$. IHC labelling of brain tissue has previously been reported to be as sensitive as FAT, with possibly increased sensitivity in autolysed tissue $[1,36]$. IHC labelling has been used as an additional confirmatory test in clinical cases $[21,35]$ but is not a routine diagnostic technique endorsed by the OIE [36]. The time taken to acquire a result, as compared to FAT, is relatively slow [29] alongside the potential for false positive or negative results as a consequence of relying on poorly trained staff [36].

Rabies viral RNA extraction from available fresh and FFPE tissue was undertaken with subsequent successful HnRT-PCR and Taqman RT-PCR testing of fresh tissue. The results from this were in full agreement with the IHC diagnoses, providing evidence of concordance between the two methods in the absence of FAT testing. The artefact score of the tested samples encompassed the full range of observed preservation (score 0 to 3). PCR has previously been reported as a very reliable method for rabies diagnosis despite sample deterioration, which appears to have been the case in this study $[8,25]$.

The PCR tests undertaken using FFPE tissues from Sri Lanka were negative. The primers used (JW12-JW6dpl) for HnRT-PCR have an analytical sensitivity of 0.01 $\mathrm{FFD}_{50}$ [2] but the amplified fragment is relatively large at 606 base pairs [21]. Samples that have been fixed in formalin, and particularly prolonged fixation at warm temperatures, are subject to RNA fragmentation: this may be from formalin induced cross linking, RNAse activation or both $[4,6,22]$. This fragmentation means that retrieval of intact large sequences above approximately 200-300 bp from FFPE tissue has been shown to be unlikely to succeed [22]. This may explain the negative results using HnRT-PCR and implies that this technique is unlikely to ever succeed on formalin fixed tissue unless alternative extraction methods, which reverse formalin induced cross linking, are developed.

The Taqman RT-PCR (JW12 and N165-146) is reported to be 200 fold more sensitive than the HnRTPCR, with a much shorter amplicon of approximately 100 base pairs $[16,34]$. This assay is therefore more likely to provide positive results from infected FFPE tissue. The Sri Lankan FFPE test material was also negative in this series however APHA processed control material was positive. The reasons for this may potentially lie in the age of the tissue, method of storage and time from processing to analysis. The Sri Lankan test material was up to 2 years older than the control tissue, subject to an unknown length of fixation and type of storage, whereas APHA material had been fixed for 7 days, processed to wax and stored in optimal humidity and temperature controlled conditions. The effect of wax embedding on RNA degradation is also unknown. Previously, real time PCR has been used to amplify a 126 bp sequence successfully for typing of a specific African Lyssavirus (isolate 864/09) from formalin fixed (but not paraffin embedded) tissue [7]. This might mean that results using formalin fixed, but unprocessed material may be more likely to be successful. This would reflect commonly encountered diagnostic field samples.

In this series, detailed anatomical and cellular analysis was not appropriate because of sample degeneration; 
however this reflects the nature of 'field' cases. Additionally every anatomical region was not available for each case. The cerebrum was over represented, possibly because the most dorsal structure is large and therefore relatively easy to sample when the entire brain is exposed at necropsy or if the prosector is unfamiliar with rabies diagnosis; for similar reasons the brain stem is under represented.

\section{Conclusions}

HE examination is essential to define the differential diagnoses of behaviour modifying conditions in rabies virus negative cases and for future analysis of viral pathogenesis, but it is unreliable as the sole method for rabies diagnosis, particularly where artefactual change has occurred. Formalin fixation and paraffin embedding does not prevent detection of rabies virus via IHC labelling even where artefactual degeneration has occurred. This could represent a pragmatic secondary assay for rabies diagnosis in the field because formalin fixation is a convenient and economical way to prevent sample degeneration. The brain stem was shown to be the site with most viral immunoreactivity, supporting recommended sampling protocols in favour of improved necropsy safety in the field. The use of HnRT-PCR for testing of FFPE tissue is unlikely to be successful but Taqman RT-PCR may offer a better chance for success.

\section{Abbreviations \\ FAT: Fluorescent antibody test; FFPE: Formalin fixed paraffin embedded; HE: Haematoxylin and eosin; HnRT-PCR: Hemi nested reverse transcription polymerase chain reaction; IHC: Immunohistochemical; PCR: Polymerase chain reaction; RT-PCR: Reverse transcription polymerase chain reaction}

\section{Acknowledgements}

The authors wish to thank Katja Voller for excellent technical assistance.

\section{Funding}

The authors acknowledge the support of Commonwealth Scholarship Commission through the Academic Fellowship LKCF-2011-210 for this study (Sri Lanka) and UK Defra, Scottish Government and Welsh Government under project SE0426 (APHA). The funding bodies had no role in the design of the study, collection, analysis or interpretation of data nor in writing the manuscript.

\section{Availability of data and materials}

All data supporting our findings are present within the manuscript.

\section{Authors' contributions}

SB carried out histopathological, immunohistochemical and statistical analysis and drafted the manuscript. PG carried out histopathological and immunohistochemical analysis. DLH participated in the acquisition of funding, conception and coordination of the study including molecular testing. DJH participated in the conception and coordination of the study including immunohistochemical testing. DM carried out molecular testing. AOP participated in the conception of the study; specifically the statistical analysis and carried out statistical tests. ARF participated in the acquisition of funding, conception, design and coordination of the study. AN conceived of the study, participated in its design and coordination and helped to draft the manuscript. All authors read and approved the final manuscript.

\section{Competing interests}

The authors declare that they have no competing interests.

\section{Consent to publication}

Not applicable.

\section{Ethics approval and consent to participate}

All canine tissue was made available from the archives of the Division of Veterinary Pathology of Faculty of Veterinary Medicine and Animal Science, University of Peradeniya. The dogs were submitted for examination as stray rabies suspects (non-experimental) as part of local human health protection measures and therefore consultation with an ethics committee was not required. Diagnostic material was retained, however applicable consent was not required because owners do not exist.

\section{Publisher's Note}

Springer Nature remains neutral with regard to jurisdictional claims in published maps and institutional affiliations.

\section{Author details}

${ }^{1}$ Pathology Department, Animal and Plant Health Agency, Weybridge, UK. ${ }^{2}$ Department of Veterinary Pathobiology, University of Peradeniya, Peradeniya, Sri Lanka. ${ }^{3}$ Animal and Plant Health Agency, Weybridge, UK. ${ }^{4}$ Wildlife Zoonoses and Vector Borne Diseases Research Group, Animal and Plant Health Agency, Weybridge, UK.

Received: 3 February 2016 Accepted: 3 April 2017

Published online: 12 April 2017

References

1. Arslan A, Saglam Y, Temur A. Detection of rabies viral antigens in nonautolysed and autolysed tissues by using an immunoperoxidase technique. Vet Rec. 2004;155:550-2.

2. Babu A, Manoharan S, Ramadass P, Chandran N. Evaluation of RT-PCR assay for routine laboratory diagnosis of rabies in post mortem brain samples from different species of animals. Indian J Virol. 2012;23:392-3963.

3. Beauregard $M$, Boulanger $P$, Webster $W$. The use of fluorescent antibody staining in the diagnosis of rabies. Can J Comp Med Vet Sci. 1965:29:141-7.

4. Ben-Ezra J, Johnson D, Rossi J, et al. Effect of fixation on the amplification of nucleic acids from paraffin embedded material by the polymerase chain reaction. J Histochem Cytochem. 1991;39:351-4.

5. Bingham J, van der Merwe M. Distribution of rabies antigen in infected brain material: determining the reliability of different regions of the brain for the rabies fluorescent antibody test. J Virol Methods. 2002;101:85-94.

6. Bussolati $G$, Annaratone L, Medico E, et al. Formalin fixation at low temperature better preserves nucleic acid integrity. PLoS One. 2011; doi:10.1371/journal.pone.0021043.

7. Coertse J, Nel L, Sabeta C, et al. A case study of rabies diagnosis from formalin-fixed brain material. J S Afr Vet Assoc. 2011:82:250-3.

8. David D, Yakobson B, Rotenberg D, et al. Rabies virus detection by RT-PCR in decomposed naturally infected brains. Vet Microbiol. 2002;87:111-8.

9. Dyer J, Niezgoda M, Orciari L, et al. Evaluation of an indirect rapid immunohistochemistry test for the differentiation of rabies virus variants. J Virol Methods. 2013;190:29-33.

10. Finnegan C, Brookes S, Johnson N, et al. Rabies in North America and Europe. J R Soc Med. 2002;95:9-13.

11. Fooks A, Banyard A, Horton D, et al. Current status of rabies and prospects for elimination. Lancet. 2014; doi:10.1016/S0140-6736(13)62707-5.

12. Fooks A, Johnson N, Freuling C, et al. Emerging technologies for the detection of rabies virus: challenges and hopes in the 21st century. PLoS Negl Trop Dis. 2009; doi:10.1371/journal.pntd.0000530.

13. Fooks A, McElhinney L, Horton D, et al. Molecular tools for rabies diagnosis in animals. In: Fooks A, Müller T, editors. OIE, compendium of the OIE global conference on rabies control. Paris: World Organisation for Animal Health; 2012. p. 75-87.

14. Franka R, Smith T, Dyer J, et al. Current and future tools for global canine rabies elimination. Antivir Res. 2013;100:220-5.

15. Goldwasser R, Kissling R. Fluorescent antibody staining of street and fixed rabies virus antigens. Proc Soc Exp Biol Med. 1958;98:219-23.

16. Hayman D, Banyard A, Wakeley $P$, et al. A universal real-time assay for the detection of Lyssaviruses. J Virol Methods. 2011;177:87-93.

17. Heaton $P$, Johnstone $P, M c E l h i n n e y ~ L$, et al. Heminested PCR assay for detection of six genotypes of rabies and rabies related viruses. J Clin Microbiol. 1997;35:2762-6. 
18. Hicks D, Nunez A, Banyard A, et al. Differential chemokine responses in the murine brain following lyssavirus infection. J Comp Pathol. 2013;149:446-62.

19. Hicks D, Nunez A, Healy D, et al. Comparative pathological study of the murine brain after experimental infection with classical rabies virus and European bat lyssaviruses. J Comp Pathol. 2009;140:113-26.

20. Johnson N, Freuling C, Horton D, et al. Imported rabies. European Union and Switzerland, 2001 - 2010. Emerg Infect Dis. 2011;17:753-4.

21. Johnson N, Nunez A, Marston D, et al. Investigation of an imported case of rabies in a juvenile dog with atypical presentation. Animals. 2011;1:402-13.

22. Kashofer K, Viertler C, Pichler M, Zatloukal K. Quality control of RNA preservation and extraction from paraffin embedded tissue: implications for RT-PCR and microarray analysis. PLoS One. 2013; doi:10.1371/journal.pone. 0070714.

23. Leach C. Comparative methods of diagnosis of rabies in animals. Am J Public Health. 1938:28:162-6.

24. Marston D, Horton D, Ngeleja C, et al. Ikoma lyssavirus, highly divergent novel lyssavirus in an African civet. Emerg Infect Dis. 2012;18:664-7.

25. McElhinney L, Marston D, Brookes S, Fooks A. Effects of carcase decomposition on rabies virus infectivity and detection. J Virol Methods. 2014;207:110-3.

26. McQueen J, Lewis A, Schneider N. Rabies diagnosis by fluorescent antibodyits evaluation in a public health laboratory. Am J Public Health. 1960;50: 1743-52.

27. Moore D, Sischo W, Hunter A, Miles T. Animal bite epidemiology and surveillance for rabies post exposure prophylaxis. J Am Vet Med Assoc. 2000;217:190-4.

28. Nietfield J, Rakich P, Tyler D, Bauer R. Rabies-like inclusions in dogs. J Vet Diagn Investig. 1989;1:333-8.

29. Rupprecht C, Hanlon C, Hemachudha T. Rabies re-examined. Lancet Infect Dis. 2002:2:327-43.

30. Shuangshoti S, Thepa N, Phukpattaranont P, et al. Reduced viral burden in paralytic compared to furious canine rabies is associated with prominent inflammation at the brain stem level. BMC Vet Res. 2013:9:31-41.

31. Stein L, Rech R, Harrison L, Brown C. Immunohistochemical study of rabies virus within the central nervous system of domestic and wildlife species. Vet Pathol. 2010;47:630-6.

32. Suja M, Mahadevan A, Madhusudhana S, et al. Neuroanatomical mapping of rabies nucleocapsid viral antigen distribution and apoptosis in pathogenesis in street dog rabies - an immunohistochemical study. Clin Neuropathol. 2009;28:113-24

33. Suja S, Mahadevan A, Madhusudana S, Shankar S. Role of apoptosis in rabies viral encephalitis: a comparative study in mice, canine and human brain with a review of literature. Pathol Res Int. 2011; doi:10.4061/2011/374286

34. Wakeley $\mathrm{P}$, Johnson $\mathrm{N}$, McElhinney $\mathrm{L}$, et al. Development of a real-time, TaqMan reverse transcription-PCR assay for detection and differentiation of lyssavirus genotypes 1, 5, and 6. J Clin Microbiol. 2005:43:2786-92.

35. White J, Taylor S, Wolfram K, O'Conner B. Case report: rabies in a 10 week old puppy. Can Vet J. 2007:48:931-4.

36. World Organisation for Animal Health (OIE). Rabies. In: Manual of Diagnostic Tests and Vaccines for Terrestrial Animals. OIE. 2015. http://www.oie.int/ international-standard-setting/terrestrial-manual/access-online/ Accessed 2 Jan 2016.

\section{Submit your next manuscript to BioMed Central and we will help you at every step:}

- We accept pre-submission inquiries

- Our selector tool helps you to find the most relevant journal

- We provide round the clock customer support

- Convenient online submission

- Thorough peer review

- Inclusion in PubMed and all major indexing services

- Maximum visibility for your research

Submit your manuscript at www.biomedcentral.com/submit

C Biomed Central 